\title{
PATRIMONIO JESUÍTICO GUARANÍ (ARGENTINA): ENTRE CONFLICTOS Y POTENCIALIDADES
}

Jesuit Guaraní Heritage (Argentina): Between Conflicts and Potentialities

\author{
Gabriel Comparato ${ }^{1}$ \\ Alumine Gorgone ${ }^{2}$ \\ Recibido: abril, 2018 // Aceptado: junio, 2018
}

RESUMEN

El presente trabajo tiene como objeto principal reflexionar acerca de los modos de activación patrimonial y los procesos de constitución de la oferta turística en sitios que han sido inscritos a la Lista de Patrimonio Mundial (UNESCO). Para ello se analiza el uso turístico de las Misiones Jesuíticas Guaraníes de la República Argentina y, con ello, se conjugan una serie de contradicciones. Específicamente, se trata de un caso que posee el máximo reconocimiento internacional en lo referido a patrimonio junto a una reconocida atractividad turística pero que, en la práctica, convive con numerosos dilemas de gestión y, en especial, de desarrollo. Metodológicamnte combina un camino deductivo originado a partir de un análisis bibliográfico interdisciplinario vinculado a la relación entre turismo y patrimonio mundial, incluyendo una reflexión sobre los paradigmas de activación patrimonial y su relación con el desarrollo. En este sentido, es un antecedente que pone en evidencia la necesidad de desarrollar políticas culturales, patrimoniales y turísticas de manera interdependientes entendiendo que ello tiene importantes consecuencias en el desarrollo de las comunidades locales que habitan dichos territorios. Como estrategia reflexiva se propone repensar el concepto de "cultura" ${ }^{3}$, entendiéndola como proceso más que como característica, cosa o entidad definida e inherente (Wright, 1998) y, con ello, las consecuencias que pueden surgir en función de que un contexto

1 Licenciado en Turismo, Magister en Integración Latinoamericana. Instituto de Investigaciones en Turismo -FCE- Universidad Nacional de la Plata. Líneas de Investigación: Gestión turística del patrimonio y epistemología del turismo. Dirección: Calle $6 \mathrm{~N}^{\circ}$ 777, La Plata (1900), Buenos Aires, Argentina. Teléfono: 54 (0221) 4236769/71/72 int. 154. E-mail: gabriel.comparato@econo.unlp.edu.ar

${ }^{2}$ Licenciada en Turismo (UNLP), Diplomada en Antropología Social y Política (FLACSO. Instituto de Investigaciones en Turismo -FCE- Universidad Nacional de la Plata. Líneas de Investigación: Antropología del turismo. Dirección: Calle 6 № 777, La Plata (1900), Buenos Aires, Argentina. Telefono: 54 (0221) 4236769/71/72 int. 154. Email: alumine.gorgone@econo.unlp.edu.ar

${ }^{3}$ La decisión de poner entre comillas deviene de poner en evidencia la conceptualización esencialista tradicional de la cultura. 
socio-histórico particular oficie de punto central representativo de todo un conjunto patrimonial.

Palabras clave: Patrimonio, turismo, cultura, impactos, Misiones Jesuíticas Guaraníes

ABSTRACT

The main objective of this work is to reflect on the modes of heritage activation and the processes of constitution of the supply of tourism in sites that have been inscribed in the World Heritage List (UNESCO). For this, the tourist use of the Guaraní Jesuit Missions of the Argentine Republic is analyzed and, with it, a series of contradictions are combined. Specifically, it is a case that has the highest international recognition in terms of heritage along with a recognized tourist attractiveness but, in practice, coexists with numerous management and, especially, development dilemmas. Methodologically, it combines a deductive path originated from an interdisciplinary bibliographic analysis, linked to the relationship between tourism and world heritage, including a reflection on the paradigms of heritage activation and its relationship with development. In this sense, it is an antecedent that highlights the need to develop cultural, heritage and tourism policies in an interdependent way, understanding that this has important consequences in the development of the local communities that inhabit these territories. As a reflexive strategy, we propose to rethink the concept of "culture”, understanding it as a process rather than as a characteristic, thing or entity defined and inherent (Wright, 1998) and, with it, the consequences that may arise depending on the socio-economic, historical context that may particularly be representative of a whole heritage site.

Key words: Heritage, Tourism, Culture, Impacts, Guaraní Jesuit Missions

\section{INTRODUCCIÓN}

No son pocos los trabajos que analizan los múltiples impactos que el turismo puede generar en sitios que han sido reconocidos dentro del marco internacional. En este sentido, es común identificar dentro de literatura especializada que la inscripción de un sitio en la Lista del Patrimonio Mundial (LPM) tiene efectos tales como el reconocimiento de los valores del sitio por la comunidad mundial y la posibilidad de acceder a un sistema de cooperación internacional para su conservación y gestión. A la vez, el prestigio de la Lista y la difusión de los bienes a cargo de la misma UNESCO provocan que uno de los efectos más evidentes sea generalmente el incremento del número de visitantes y en un mayor posicionamiento del destino. Pero el “quid” de la cuestión se relaciona con que dichos efectos no constituyen garantía alguna de desarrollo y, de no 
mediar una adecuada planificación integral, los efectos negativos pueden amenazar a las comunidades locales que habitan esos territorios, poniendo en riesgo sus sistemas de vida tradicionales y su propia identidad sociocultural así como también profundizar situaciones de exclusión social.

En virtud de lo anterior, el presente trabajo pretende operar en dos planos simultáneamente. Por un lado, un plano más general asociado a reflexionar acerca de los modos de activación patrimonial y los procesos de constitución de la oferta turística en sitios que han sido inscritos a la Lista de Patrimonio Mundial (UNESCO). Y, a la vez, un segundo eje, más particular, que analiza el uso turístico de las Misiones Jesuíticas Guaraníes de la República Argentina y que intentará poner en valor una serie de contradicciones resultantes de dicho proceso. Se entiende que ese uso turístico está determinado en gran medida por un proceso de valorización acorde a la "mirada del turista"(demanda) que puede, en algunos casos, cambiar el significado inicial que se le atribuyó a esos bienes por medio del proceso de patrimonialización (Almirón, Bertoncello, Troncoso, 2006; Bertoncello, 2008). En este sentido, al analizar conjuntamente la significación otorgada por la UNESCO y la oferta turística, se encuentra toda una gama de problemáticas y deficiencias, pero también de oportunidades.

Ahora bien, para encarar tal análisis se propone como estrategia fundamental la necesidad de no escindir la teoría de la práctica concreta. Es decir, de pensar y representar la “cultura(s)” tratando de superar el viejo paradigma que la define como totalidad ahistórica, autocontenida, estática, homogénea en su interior, para pasar a concebirla como dinámica, fluida y construida situacionalmente (Wright, 1998). Como tal, el estudio no solo cobra relevancia por poner en juego una articulación teórico-práctica sino de poner en diálogo dimensiones que no hacen referencia exclusivamente al turismo, pero que sí se interrelacionan, como los procesos históricos, identitarios y modelos de acumulación. Debate que requiere superar el campo específicamente turístico para ir en búsqueda de una articulación trans-disciplinar.

Metodológicamente, el presente constituye un avance del proyecto de investigación bianual Impactos del turismo en los sitios de Patrimonio Mundial en Argentina y su relación con el desarrollo sostenible (20162017) llevado adelante por el Instituto de Investigaciones en Turismo, Universidad de la Plata, Argentina. En dicho marco se combina un camino 
deductivo originado a partir de un análisis bibliográfico interdisciplinario vinculado a la relación entre turismo y patrimonio mundial, incluyendo una reflexión sobre los paradigmas de activación patrimonial y su relación con el desarrollo. Por otra parte, en sentido inverso, se pretende realizar una interpelación teórica a partir del análisis del caso. Para ello se incorpora información primaria producto de la visita a los sitios y entrevistas semi-estructuradas a informantes claves durante los meses de mayo y julio de 2016. Todo ello permitirá realizar ejercicios de triangulación metodológica de manera de contribuir a realizar un análisis más integral y reflexionar sobre potencialidades y conflictos que conviven en la región. Vale aclarar, en este sentido, que la información aquí expuesta se centrará en los sitios argentinos inscritos a la Lista de Patrimonio Mundial (1984) pero a la vez, como se verá, se reconoce la importancia de no descontextualizar estos casos de toda la serie trasnacional (Brasil, Paraguay y Argentina).

\section{MISIONES JESUÍTICAS GUARANÍES (ARGENTINA): UN CONTEXTO}

Las misiones jesuíticas guaraníes, también denominadas reducciones o misiones del Paraguay, constituyen un antecedente de gran relevancia para la historia de la región transfronteriza de Brasil, Argentina y Paraguay. Las mismas se desarrollaron desde el año 1609 hasta 1767, momento de la expulsión de los jesuitas, y constituyen una experiencia histórica, religiosa, sociocultural, económica y territorial excepcional en función de su reconocimiento internacional. Se emplazaron en un amplio espacio conformado por las actuales provincias de Misiones y Corrientes en la Argentina, sudeste de Paraguay y sudoeste del Estado de Río Grande do Sul, en Brasil, logrando erigir un total de 30 pueblos jesuíticos guaraníes (Rivero y otros, 2011, p. 112). No obstante, en lo que refiere a su nominación a patrimonio mundial, el primer punto a destacar es que el sistema jesuítico no fue incorporado en su totalidad al momento de ser inscrito en la Lista de Patrimonio Mundial (LPM). Por una parte, se seleccionaron siete de las treinta misiones que tuvieron emplazamiento en la región y, por otra, no todos tuvieron la misma fecha de reconocimiento internacional. En efecto, la primera declaración corresponde a Brasil en 1983 con su correspondiente extensión, a partir de la incorporación de los 
cuatro sitios argentinos, en 1984 mientras que el reconocimiento de los dos sitios de Paraguay datan de 1993 (Comparato, 2016, p. 191).

En lo que respecta a la distribución espacial, la mayoría se localiza en un territorio dividido en tres fajas casi paralelas con orientación nordeste-sudoeste. Argentina es el país de mayor concentración (con un total de 15), siguiéndole, en orden, Paraguay (8) y Brasil (7) respectivamente; aunque no todas siguen en pie o son posibles de ser visitadas. Si consideramos lo que constituye el soporte físico y geográfico, se trata de una región atravesada por numerosos ríos y arroyos, en el marco de una densa vegetación, por lo que la caracterizan altas temperaturas y precipitaciones al igual que una gran biodiversidad. A modo general, la localización de las misiones se da en puntos con gran valor paisajístico, en zonas que están elevadas por alguna meseta con amplio horizonte. Tal como señala Viñuales (2007, p. 115) esta federación de pueblos no comprendía solo a una serie de poblaciones urbanas, sino que se complementaba con estancias y yerbales que ocupaban una vasta región. De hecho, apenas en un quinto de esta superficie se encontraban ubicados los pueblos.

Imagen I: Localización de las Misiones Jesuíticas Guaraníes inscritas a la LPM
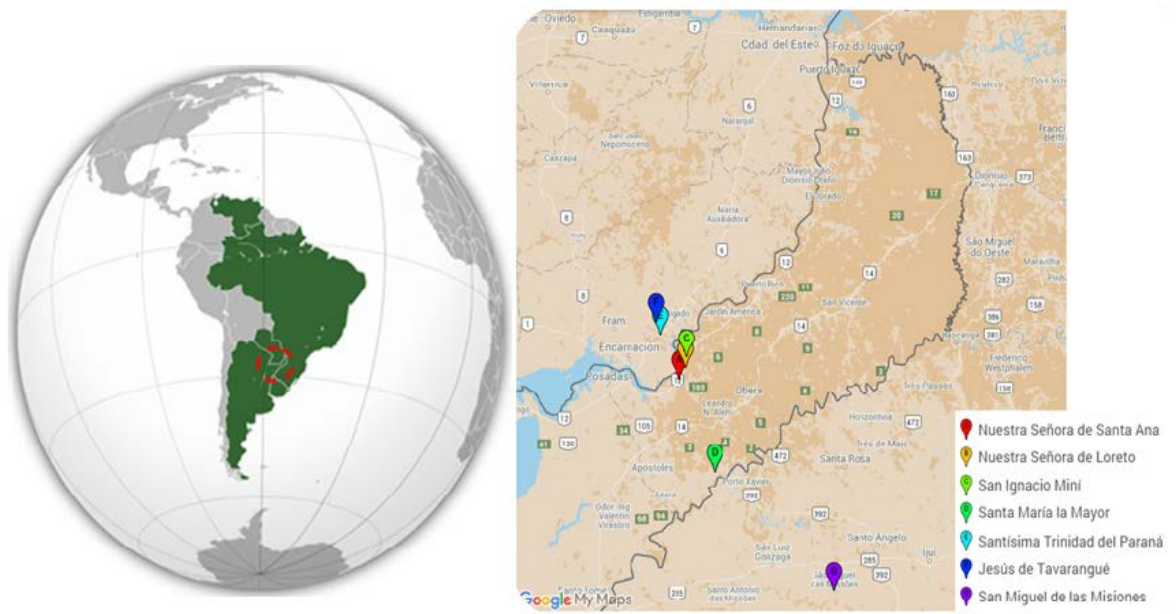

Fuente: Comparato (2016, p. 201) 
Lo anterior implica identificar, en primera instancia, a la región como un transterritorio que tiene continuidades en términos de procesos históricos, relaciones sociales y modelos de acumulación pero, al mismo tiempo, con diferenciaciones propias de las demarcaciones espaciales propias de los tres Estados que implican respectivos ordenamientos urbanos, jurídicos, económicos y políticos. Dado que el presente trabajo se centra en los sitios argentinos inscritos a la Lista de Patrimonio Mundial, el primer punto a referenciar es que la provincia de Misiones se ubica en el extremo noreste de la República Argentina, limitando al oeste con la República del Paraguay, al norte y este con Brasil y al sur, con la provincia de Corrientes. De esto resulta que un $90 \%$ de sus fronteras son internacionales. Pese a su reducida superficie, su ubicación geográfica la sitúa en el centro de una gran región, la Cuenca del Plata, con una especial significación geopolítica y comercial (Ministerio de Agricultura, Ganadería y Pesca; Misiones: 2009, p. 3-12). Se trata, asimismo, de la segunda provincia argentina con mayor densidad poblacional de todo el país, con 37 habitantes por km2, número superior al de las provincias del litoral argentino y tiene una población aproximada de 1,1 millones de habitantes (INDEC, 2010). No obstante, tal como indican algunas estadísticas, como el "Informe Nacional sobre Desarrollo Humano (2013)”, Misiones es una de las provincias argentinas que presenta los menores niveles de desarrollo humano de todo el país, solo superando los casos de Formosa, Chaco y Santiago del Estero (PNUD, 2013, p. 34). A esto se le suma un bajo nivel de participación ciudadana, concentrada principalmente en niños y jóvenes (Plan de Competitividad Turística del Corredor Iguazú-Misiones, 2007, p. 18). La posición geográfica de la provincia le otorga una condición de “bisagra” entre los tres países (Cammarata, 2010, p. 14). Posadas, por su parte, es su capital y tiene una población cercana a los 300 mil habitantes para 2010 (INDEC, 2010) siendo la ciudad más poblada de la provincia y concentrando casi el 30\% de la población, siendo Oberá e Iguazú los departamentos que le siguen en importancia. En cuanto a su matriz productiva, sus principales actividades económicas están ligadas a la producción de té, yerba, soja, algodón, caña de azúcar, entre otros y a la silvicultura. Por su parte, su sector secundario está directamente relacionado con lo anterior en tanto que se centra en la agroindustria y la industria forestal.

En virtud de lo anterior es preciso poner en evidencia el carácter transfronterizo y dialéctico del territorio hacia ambas márgenes de los ríos 
Uruguay y Paraná. Tal como sugiere Cammarata (2010, p. 11-13) se trata un espacio o paisaje con una gran interacción económica y social, con una población caracterizada por la presencia de pequeños y medianos productores rurales, con una historia similar en lo relacionado a formas de ocupación de la tierra, así como también con tradiciones y códigos culturales compartidos. Es decir, una matriz sociocultural común que no solo incluye raíces históricas, procesos de poblamiento similares, interrelaciones fronterizas casi nunca interrumpidas, varias lenguas y códigos culturales compartidos, sino también comercio y contrabando. Manzanal y otros (2011, p. 60) sostienen que mientras algunos se benefician producto de la expansión acelerada de ciertos cultivos como la soja, otros se perjudican con la pérdida de diversidad, con la expulsión de familias y productores y abandono de actividades tradicionales. Tendencias acompañadas por un proceso de extranjerización y de concentración de la tierra y con la existencia de relaciones de poder desiguales, sobre todo para el pequeño productor. Diversidad que también se asocia a la matriz pluricultural, no solo por la herencia hispanoguaranítica que tuvo la región, sino por los procesos inmigratorios que la caracterizaron a fines del siglo XIX y principios del XX. Se destaca, por tanto, un territorio que manifiesta disputas, disparidades y conflictos latentes. Asimismo, esta región es lugar de grandes obras de infraestructuras, tales como las represas hidroeléctricas compartidas como es el caso de Itaipú, al norte del caso de estudio (Paraguay- Brasil) y Yacyretá al sur (Argentina-Paraguay). Esto le otorga, según Schweitzer (2009, p. 314-321) la categoría de una de las áreas más dinámicas en lo que concierne la formación de territorios en las fronteras interiores del Mercosur. Por tanto, según el autor, el desarrollo comercial, a partir de la complementación entre el enclave turístico y el energético, es una de las explicaciones que permite entender por qué la región constituye uno de los mayores polos de integración fronteriza, sin estar con ello exento de conflictividad social (entre los que se destacan los altos niveles de explotación de la fuerza de trabajo y el comercio informal). Asimismo, se manifiestan una serie de conflictos que establecen interrogantes en relación a los escenarios futuros, tal como la distribución de la tierra producto de una tendencia a la concentración y a su extranjerización, así como también la protección de los remanentes de bosque nativo consecuencia de la ampliación de las áreas forestales y ganaderas en detrimento de la agricultura familiar (Kramer, 2013, p. 14). 
En cuanto a la categorización de este producto turístico, a distintas escalas y con diversos matices y contrastes, el producto "Misiones Jesuíticas” se enmarca en un perfil en el que históricamente predominaron los recursos naturales como atractivos turísticos principales (agua, selva, cascada, sierras). Es decir, en un marco donde la relación turismo y patrimonio estuvo fuertemente ligada al paisajismo y a la contemplación. Desde mediados de los 90, y sobre todo a partir del siglo XXI, aparecerá en el discurso político, así como de varias iniciativas privadas, la necesidad de diversificación de la oferta turística y la puesta en valor de otros recursos. Comenzarán el posicionamiento de los espacios rurales, de su patrimonio intangible diverso, de nuevos eventos y espacios culturales; y señales de búsqueda de un turismo más activo y participativo.

Si el objetivo es describir el sistema jesuítico guaraní desde su uso turístico, se podría sostener, a modo general, que se trata de un producto a partir de un conjunto de atractivos que es comercializado en el marco del turismo religioso y/o turismo cultural, entendido como aquella práctica que tiene a la cultura y al patrimonio cultural como principal recurso atractor de la actividad turística. Esta modalidad, entendida en un sentido amplio, le permite mutar, según el caso, desde la creación de experiencias genéricas de promoción y divulgación de los valores patrimoniales, así como también la creación de productos específicos para segmentos de turistas con demandas especiales, como por ejemplo el turismo místico y de peregrinación o de turismo rural con base comunitaria, en este caso guaraní. Si bien estas áreas no poseen aún una matriz turística diversificada, las características paisajísticas asociadas con el clima subtropical, una gran cubierta vegetal, abundancia de recursos hídricos y una importante biodiversidad le permiten agregar valor a los sitios estrictamente culturales y, al mismo tiempo, le otorgan una gran aptitud de complementación de dichos productos con formas de turismo más asociadas a la naturaleza (como el ecoturismo). Planteado de esta manera, las formas de turismo que tienen como objeto principal la observación y apreciación de la naturaleza le otorgan, incluso, ventajas comparativas cuando forman parte del mismo producto turístico o, en su defecto, ser un complemento a la oferta cultural. Al mismo tiempo, se destaca como potencialidad el uso turístico del patrimonio intangible, asociado a comidas típicas, danzas, tradiciones, rituales, saberes o música. No solo a los efectos de diversificación y complementación de la oferta turística, sino también a los fines de generar experiencias multisensoriales capaces de 
diferenciar a los destinos respecto de otros. El mate, el chipá, los coros, las artesanías guaraníes sumado a un gran número de prácticas/ tradiciones traídas y adaptadas en los procesos de inmigración, pueden ser promotores culturales y, al mismo tiempo, focos atractores de turismo.

Ahora bien, desde una óptica analítica se podría destacar algunos patrones generales que caracterizan a la literatura referida al tema. En este sentido, pareciera evidente la existencia de un consenso en destacar que: se trata de un bien con un gran valor histórico y que presenta grandes atributos de atractividad, pero que todavía tiene mucho para aportar en términos de desarrollo local y de desenvolvimiento turístico (Vilmar Satur, 2000, p. 13; Silveira Alves, 2007, p. 12; Bittencourt y Veroneze Stigliano, 2011, p. 1390). Por otra parte, y si bien las Misiones Jesuíticas Guaraníes son catalogadas desde la esfera pública como producto turístico, esto ha tenido un mayor grado de debate y puesto en discusión desde el ámbito académico-investigativo (Del Rio, 2007, p. 61; Nogueira y Burkhard, 2008, p. 10). Se podría agregar, en términos técnicos, que este producto, pese a sus avances y reconocimientos institucionales, todavía permanece con una apuesta fuerte en sus ventajas comparativas relacionadas con su dotación de recursos patrimoniales. Es decir, con déficits que tienen que ver con las capacidades de gestión y la puesta en valor de otras capacidades, recursos y elementos patrimoniales.

Por su parte, los estudios de demanda llevados adelante por el Ministerio de Turismo de Misiones (2014, 2017) evidencian, todavía, un fuerte posicionamiento de los atractivos naturales tradicionales acompañado de bajos niveles de pernoctación en los destinos y marcada estacionalidad, sobre todo de aquellos directamente vinculados a las Misiones Jesuíticas, como San Ignacio, Loreto, Santa Ana o Santa María la Mayor. Asimismo de la lectura bibliográfica, sobre todo en lo que concierne a las Universidades de la región (Dieckow, 2003, 2012; Cubas, 2006; Rivero y otros., 2011) parecería existir una tendencia a caracterizar a la actividad turística asociada a un modelo de desarrollo de "enclave", en tanto que se evidencia: bajos niveles de efecto multiplicador, bajos niveles de pernocte, impactos concentrados en determinados sitios, una importante generación de empleo de tipo informal y precarizado, así como también una participación de la comunidad local limitada asociada a actividades muy puntuales -como la venta de artesanías-.

En virtud de lo anterior, el "Plan de competitividad turística del corredor Iguazú Misiones“ (2007, p. 22-23) sostiene que Cataratas del 
Iguazú constituye un destino polarizador de la actividad turística de la provincia argentina, lo que le confiere una doble lectura. Por una parte, el corredor trasciende las ciudades de Posadas y Puerto Iguazú y registra tres áreas principales: 1) Área de las Misiones Jesuíticas; 2) Área de los Municipios Centrales y 3) Área de influencia de Iguazú, pero, al mismo tiempo, el cluster se encuentra en un estado embrionario debido a la fuerte desarticulación existente entre el área de influencia de Iguazú y el resto del corredor. En otras palabras, la oferta basada en la espectacularidad de su recurso más conocido, Cataratas ${ }^{4}$, ha permitido un cierto avance en la mejora de su oferta turística, pero también ha generado una excesiva dependencia y se ha expresado en un desarrollo turístico desequilibrado. Se podría agregar, incluso, la necesidad de articulación de corredores esteoeste debido a la dependencia casi exclusiva norte-sur. Por otra parte, es preciso observar que así como se destacan ciertas continuidades históricas existen otros procesos que han alterado ciertas dinámicas turísticas características de la región, o al menos en parte. Una de ellas es el posicionamiento de los últimos años del turismo de sol y playa en Encarnación (Paraguay) en tanto que logró captar la visita (en época estival) de un importante número de turismo doméstico paraguayo (así como regional). Lo anterior se dio a raíz de la subida del nivel del río producto de la ampliación de la represa de Yacyretá, río abajo. En este sentido, con la inauguración de la primera costanera en 2010 la ciudad adquiere una reconversión urbana y turística posicionándose como un destino de sol y playa provisto de un circuito comercial al que se le suman otras manifestaciones culturales tales como el carnaval.

Ahora bien, el punto es que lo antes descrito no se inserta en cualquier espacialidad, sino en una que está atravesada por bajos niveles de desarrollo humano (PNUD, 2013) en comparación con los indicadores nacionales y con cuadros de empobrecimiento ligados sobre todo al ámbito rural. Ello, entre otras razones, genera que coexistan asimetrías de poder $\mathrm{y}$, en determinadas oportunidades, fuentes de conflicto, sobre todo con problemáticas vinculadas a la tenencia de la tierra y al avance y

\footnotetext{
${ }^{4}$ Es interesante destacar que las Cataratas del Iguazú reciben esta característica de espectacularidad en el marco de la primera etapa de constitución de Parques Nacionales en el país, siendo su valor paisajístico monumental la justificación de su protección (Caruso, 2015). Esta significación marcó fuertemente su imaginario a nivel nacional e internacional, cuestión no menor a la hora de pensar la atractividad.
} 
profundización de la frontera agropecuaria, en detrimento del monte nativo y los pueblos originarios. A lo anterior se le suma la convivencia de una marcada multiculturalidad y diversidad lingüística, en consonancia con la convivencia de guaraní y descendientes, el sincretismo propio del avance español y portugués, así como los procesos inmigratorios posteriores que le continuarán. Esto, como tal, marca un territorio diverso, con contrastes, que otorga grandes potencialidades, pero al mismo tiempo pone en evidencia la coexistencia de una importante actoralidad con lógicas idiosincráticas diferentes. También son parte de este proceso los altos niveles de explotación de la fuerza de trabajo y el comercio informal y que, en el caso del comercio de fronteras, se constituyen alianzas de actores locales hegemónicos transfronterizos, que se proyectan (Schweitzer, 2009, pp. 9-14).

El punto de la cuestión tiene que ver, además, con que varias de las problemáticas que tienen lugar en el territorio, se visualizan/trasladan también al campo específico de la práctica turística. De la visita a los diferentes sitios, se pudo observar, en general, un rol "limitado", "secundario" o "subsidiario"que se le otorgan a las comunidades locales. Esto se observa, por ejemplo, en el tipo de actividades que los locales desempeñan dentro del concepto de desarrollo turístico, generalmente asociado a actividades de venta de artesanías, muchas veces en un ámbito informal. Kramer (2011, p. 86) observa que no se trata de un problema de falta de profesionalismo sino que la planificación, con el transcurrir del tiempo, no es acompañada con entrenamiento de la población local. De esta manera, agrega que una propuesta “innovadora” sólo se sostiene durante un tiempo y paulatinamente va declinando. De algunos testimonios personales en mayo de 2016 en Paraguay en el marco de relevamiento patrimonio se extraía lo siguiente: Poblador local de Trinidad: "los colectivos así como llegan se van” Guía del sitio de Jesús de Tavarangué: "la gente del pueblo no se acerca”, "no le da beneficios económicos"; "hay falta de integración social”Cubas (2006, p. 25), en esta línea, señala que otro de los indicadores que dan cuenta del escaso aporte del turismo a la economía local es el porcentaje de mano de obra empleada en el sector. Refiriéndose a la localidad de San Ignacio afirma que "la estructura de empleo directo se distribuye en una veintena de establecimientos dedicados a la prestación de servicios turísticos (básicamente de alojamiento y alimentación); también la venta de artesanías y souvenires en la Feria”. Pero agrega que no se trata solamente 
de una cuestión económica o laboral, sino que la problemática surge desde el proceso de patrimonialización de las ruinas, a principios del siglo XX, donde se vislumbraban los conflictos y tensiones entre los lugareños y las políticas nacionales que buscaban la protección y conservación del sitio. De hecho infiere que a principios del siglo la reducción no adquiría valor para la comuna por su importancia como recurso histórico-cultural, sino que más bien, era percibido como un conjunto en ruinas que “(...) con sus piedras desparramadas se presentaba como el sitio preferido para pasear, jugar, esconderse" (Gentiluomo de Logier, E.; 1999 citado en Cubas ob. Cit., p. 9). Ese tipo de tensiones se seguirán manifestando a lo largo de los años y entrarán en conflicto los tipos de “usos” que se pretenden del sitio, como a finales de la década de los 80, cuando se decide cambiar la funcionalidad de ciertos espacios, como la adaptación a un centro de interpretación donde previamente había una escuela.

\section{DILEMAS Y DESAFÍOS DE REPRESENTACIÓN DE LA "CULTURA"}

Como ya se ha precisado anteriormente, las Misiones Jesuíticas Guaraníes han sido destacadas por su gran valor histórico-patrimonial y consecuentemente han desarrollado procesos de activación turística. Sin embargo, se discutirán aquí algunas de las limitaciones que implica su puesta en valor a través del criterio IV de la UNESCO durante su inscripción en 1984. Lejos de proponer una crítica lineal, se busca poner en tensión cómo ciertos discursos producen performativamente la realidad de sitios patrimoniales al mismo tiempo que permite dar visibilidad a otras potenciales y benéficas formas de representación. Estas consideraciones presentan una relevancia importante, ya que permiten reflexionar sobre distintos paradigmas de activación patrimonial y formas de concebir y gestionar el desarrollo entendido en un sentido amplio.

Si se parte del carácter o condición mediante el cual el sitio fue inscrito a LPM, se trata de un bien en serie "cultural”, cuya definición adoptada por la Convención sobre la protección del patrimonio mundial, cultural y natural (1972) incluye: "monumentos”, "grupos de edificios” y "sitios": "obras del hombre o las obras combinadas de la naturaleza y del hombre, y áreas incluyendo sitios arqueológicos que son de Valor Universal Excepcional desde el punto de vista histórico, estético, etnológico o antropológico” (WHC, 2016, p. 10). Asimismo, el criterio 
que le adjudica al sitio valor universal excepcional expresa que las Misiones constituyen un ejemplo eminentemente representativo de un tipo de construcción o de conjunto arquitectónico o tecnológico que ilustra un periodo significativo de la historia humana. Específicamente el criterio mediante el cual se justifica el valor universal excepcional es: "The surviving remains of the Jesuit Missions of the Guaranis represent outstanding examples of a type of building and of an architectural ensemble that illustrate a significant period in the history of Argentina and Brazil. They are a living testament to Jesuit evangelization efforts in South America"5

De lo anterior se desarrollarán entonces una serie de propuestas que, sin ser exhaustivos, permiten una indagación a profundizar en futuros trabajos. En principio, se reconoce que si bien los aspectos urbanísticos y arquitectónicos ponen en evidencia rasgos de excepcionalidad de estos sitios arqueológicos también plantean la necesidad de actualizar y profundizar en relación a otras formas de manifestaciones identitarias incluyendo bienes intangibles y componentes naturales asociados al contexto. En este sentido, tanto las fuentes secundarias como aquellas de primera mano evidencian que los valores transmitidos durante la experiencia turística han generando una limitada significación patrimonial y turística de los bienes que integran el sistema asociado al "monumentalismo". Pero el punto es que no se trata de una simple forma discursiva abstracta, sino que esta se relaciona directa e indirectamente con el conjunto de componentes patrimoniales puestos en valor $y$, consecuentemente, con los procesos de desarrollo turístico que han tenido lugar en los sitios. A partir de esto se manifiestan tendencias de comunicación, interpretación y gestión patrimonial excluyentes hacia las identidades guaraníticas acompañado de una matriz de desarrollo caracterizada por precarización laboral, bajos promedios de pernoctación, desequilibrios territoriales e incluso temporales (estacionalidad). Se trata de un caso, que a la vez, interpela las formas de poner en valor "la cultura" y la necesidad de trascender una mirada esencialista o estática del indígena. Ello implica no circunscribir la historia de estos pueblos a un pasado particular o específico y evitar generar, con ello, una visión única e inamovible de los mismos (contando actualmente con realidades muy distintas a dicho pasado). Es decir, como afirma Restrepo (2007), la

${ }^{5}$ UNESCO, recuperado de: http://whc.unesco.org/en/list/275 (26/07/17) 
identidad es un término ambiguo en la medida que es relacional, procesual, históricamente situada, resultado de una amalgama, y por lo tanto también múltiple, provisional y contingente.

A los efectos de caracterizar muy brevemente la situación actual, se aportan algunos datos estadísticos que permiten una aproximación a la situación indígena que se encuentra en parte involucrada con el sitio, tanto física como simbólicamente. Según las estadísticas oficiales del censo Nacional de Población, Hogares y Viviendas 2010 relativos a la población que se reconoce perteneciente o descendiente de un pueblo indígena u originario, tomadas por el IPEC (Instituto Provincial de Estadísticas y Censos de Misiones) existe un total de 13006 individuos indígenas o descendientes de pueblos originarios en viviendas particulares, lo que representa el 1,2\% de la población total de la provincia de Misiones. Dentro de ese porcentaje, el 48,9\% se autorreconoció como perteneciente al pueblo Mbyá Guaraní (6 349 personas), el 32,8\% al Guaraní (4 260) y el 4,3\% al Mapuche (562). Luego le siguen los Ava Guaraní con un 3,2\% (422), los Toba (Qom) con un $2.5 \%$ (326), los Atacama con un 2.4\% (317), los Tupí Guaraní con un 1.9\% (247), y “otros” con un 4\% (523) . Un dato relevante para este estudio, es que esta población indígena se distribuye en el territorio de manera casi igualitaria en cuanto a las áreas urbanas $(57,9 \%)$ y las rurales $(42,1 \%)$. Sin embargo, el grupo más numeroso y que se problematiza con la actividad turística, el Mbyá Guaraní, es mayoritariamente rural (82,1\%), al contrario del pueblo guaraní donde el 59,6 \% reside en las ciudades. Además se denota en las cifras la tendencia de las etnias guaraníes como Tupí Guaraní y los Ava Guaraní con residencias casi igualitarias de distribución, diferenciándose de las otras etnias anteriormente consignadas, donde su población se distribuye más en las ciudades. Son importantes estas cuestiones, porque implican formas de vida, de manutención económica y culturales en general heterogéneas. Como último dato, el NEA (Misiones, Corrientes, Chaco y Formosa) es una de las regiones con mayor proporción de población originaria en zona rural (46,5\%), cuando el $81,9 \%$ de la población indígena del total del país se encuentran en zonas urbanas, esto da una visión más acabada del contexto provincial y regional dentro de un país con muchas heterogeneidades.

Según un trabajo realizado por Crivos y Pochettino (2002) y CRESPIAL (2013) la forma de vida de los Guaraní-Mbya se destaca por su amplia movilidad histórica, con una agricultura itinerante, mediante el 
sistema de roza y quema, lo cual ha llevado a que se hayan ido desplazando a lo largo de las cuencas fluviales del Paraguay, Paraná, Uruguay y Plata. Además se sustentan también con la caza, pesca, recolección de vegetales y de miel, la obtención de ingresos a través de la venta de artesanías y con trabajo temporario ligado, generalmente, a las cosechas de tabaco y yerba mate. Su organización familiar se caracteriza por familias extensas que habitan y se mueven por diferentes espacios: a) vivienda y entorno inmediato (chacras o huertos); b) monte: es decir, espacios más lejanos donde cazan, pescan y recolectan, y por último c) las rutas, colonias y espacios turísticos donde ponen sus puestos para la venta de artesanías y en donde realizan trabajos temporarios de desmonte, carpida, desyerbe $u$ otras tareas vinculadas a las plantaciones de yerba mate y tabaco. Por otro lado, Bartolomé (2008) haciendo un complejo trabajo acerca de los cambios en la cosmología de los Mbyá, destaca su singularidad y aislamiento con respecto a otros grupos guaraníes, ya que habría sido el único que mantuvo su autonomía, resistiendo a la evangelización y con luchas posteriores con los mestizos y criollos. Es decir, es un grupo que, en términos generales, se mantuvo o regresó a la selva, atravesando así diferentes procesos de reconfiguración simbólica en donde su anhelo de la búsqueda de la "tierra sin males" -mitología que guía su vida, pero así también su constitución como persona- es una conjunción de lógicas míticas mbya y cristianas. Por otra parte, el autor indica que esta doctrina salvacionista, producto de la huida de la evangelización y con influencias de un culto milenarista, habría reformulado sus sistemas simbólicos creando una configuración de etnicidad particular. Este proceso, al que categoriza como etnogénesis, produjo en términos religiosos (pero también éticos, sociales y culturales) una tradición transfigurada que, como supone el concepto, implica que los grupos sociales tienen una dinámica social histórica que va variando con el tiempo, en función de múltiples relaciones interétnicas y de procesos como migraciones, invasiones, conquistas, fisiones o fusiones. Es decir, contrario a algunos discursos o enfoques que presuponen formas culturales "puras” para determinados grupos sociales. Aunque breve, esta referencia al pueblo Mbya, nos alerta sobre la existencia de formas de vida heterogéneas, incluyendo cosmologías donde, por ejemplo, la naturaleza y la cultura no son consideradas como entidades con ontología separada. También nos permite caracterizar cierta identidad, tratando de trascender el esencialismo, pero sin quedarnos en un marco 
constructivista infinito, sino plasmando ciertas trayectorias y formas concretas (Restrepo, 2007, p. 33).

En esta línea, los guaraníes no solo residen y trabajan muchos de ellos (informalmente) en la venta de artesanías en las inmediaciones de los bienes que integran la serie patrimonial; sino que además la administración provincial de turismo apela a ellos a través del proceso de representación patrimonial y valoración turística. Esto conlleva mínimamente una pregunta en cuanto al contenido y forma de lo anterior y como consiguiente su reconocimiento como pueblo o comunidad con derechos. $\mathrm{Si}$ bien se entiende que el bien en serie ha sido reconocido como un testimonio de un proceso histórico particular, si el lineamiento de desarrollo se pretende en términos de sustentabilidad, resultaría indispensable considerar el carácter dinámico de la cultura. Es en este escenario en el que urge considerar la "cultura” en términos más amplios y dinámicos, con aspectos tangibles e intangibles, materiales e inmateriales, entendida como "proceso conflictivo de construcción de significado" en donde intervienen diferentes actores en posiciones de poder diferenciales (Wright, 1998, p. 131). Más concretamente, se postula tomar el reconocimiento patrimonial como punto de partida y no como cierre, ni representativo de la totalidad. El componente dinámico implica poner en valor voces e identidades diversas, acorde a las distintas realidades e idiosincrasias de los diferentes pueblos que conforman la región guaranítica. $\mathrm{Y}$, tal como se afirmó, ya no se trata solamente de una gestión cultural revisionista plural, sino también, en cómo ello puede contribuir a diversificar la oferta turística regional, promover mayores niveles de inclusión social y una distribución del ingreso tempoespacialmente más equitativa. Diversificar que, a la vez, implica complementar e integrar atractivos que tradicionalmente se han escindido dicotómicamente a partir del binomio cultura vs naturaleza.

Por esta razón se apela a la noción de ambiente desde dos perspectivas ontológicas diferentes que se terminan entrelazando. Como argumenta Descola (2002), solo en el Occidente moderno se da la oposición entre naturaleza y cultura como matriz ontológica de ordenación del mundo. De esta forma, la naturaleza es concebida como un objeto pasivo de acción humana (separada de ella), un recurso, que en todo caso hay que preservar para las generaciones futuras. En cambio, para diversas sociedades premodernas los seres "naturales” están dotados de alma, de 
intencionalidad y de conciencia reflexiva, es decir, la naturaleza es un sujeto de una relación social. Así, el autor afirma:

“Todas las sociedades admiten la existencia de pequeños trozos de naturaleza, si se puede decir, pero solo en el moderno Occidente se da la oposición entre naturaleza y sociedad, una función rectora dentro de su cosmología. Para escapar al etnocentrismo de esta dicotomía, parece preferible plegarse hacia una distinción menos cargada de implicaciones filosóficas, morales y epistemológicas, aquellas entre humanos y nohumanos” (Descola, 2002, p. 159).

Precisamente, propone criticar ese dualismo, partiendo de nuestro paradigma naturalista, pero retomando esas otras formas de concepción y así, reorganizando conceptos para pensar en términos de relaciones entre seres sociales y seres naturales. De esta manera sugiere la noción de ambiente como objeto legítimo de investigación antropológica.

En consecuencia, la segmentación occidental entre "natural” y “cultural” produciría por un lado no solo una visión de la cultura de estos pueblos distorsionada, sino que además excluye la posibilidad de integrar a la oferta turística el ecosistema natural en las cuales se encuentra emplazado el bien en serie. Como se mencionó en apartados anteriores la provincia de Misiones se caracteriza por poseer un clima sub-tropical húmedo y así un bioma denominado selva misionera, que es parte de una más extensa ecorregión llamada Selva Paranaense, que se extiende también por Paraguay y Brasil. Estas singularidades hacen a una riqueza ecológica de relevancia, aunque se presentan grandes problemáticas como el desmonte y deforestación para variados usos como los monocultivos intensivos. Asimismo, cuenta con varias áreas naturales protegidas, lo que sumado a la anterior, ha dado lugar a uno de las dimensiones de la oferta turística: el segmento "naturaleza”.

Dadas estas condiciones, y el emplazamiento de las Misiones Jesuíticas en un contexto natural, se detecta entonces la ausencia de una visión interpretativa más holística del conjunto, lo que conduce a un desaprovechamiento de la posibilidad de conformación de una oferta integral más inclusiva a nivel ecológico y cultural que sea más sustentable en todas sus dimensiones. Se afirma entonces que existe una potencialidad de diversificación de la oferta turística, en tanto la caracterización del sitio como patrimonio de tipo cultural y su inclusión en la oferta como "turismo 
cultural” podría ampliarse incluyendo una estrategia de comunicación y sensibilización de la importancia ambiental y paisajística del entorno que vaya más en consonancia con los universos simbólicos de los pueblos originarios guaraníes que aún residen en el territorio y para el beneficio en términos de desarrollo integral, que comprenda el territorio en todas sus dimensiones, y así en su complejidad social, económica, cultural y natural.

Por otro lado, en consonancia con el diagnóstico del sitio y de la provincia de Misiones realizado en el marco del proyecto mencionado, se determinó la baja incidencia de la "cultura” en las motivaciones de la demanda. Es decir, los estudios de demanda llevados adelante por la provincia evidencian aún una fuerte concentración en los atractivos naturales tradicionales con bajos niveles de pernoctación en los destinos, sobre todo de aquellos directamente vinculados a las Misiones Jesuíticas. En este sentido, la mayoría de los encuestados reconoce a los atractivos naturales como los elementos diferenciales que hicieron elegir la provincia respecto de otros destinos. De esta manera, aparecen fuertemente las cataratas (30,7\%), la naturaleza (15,3\%) y Moconá (7,2\%). Por otro lado, de todos los encuestados solo un $1,4 \%$ reconoce estar motivado por la “cultura y educación” mientras que la mayoría (78,2\%) afirma estarlo por “vacaciones/paseo”. Si bien se abren repreguntas en torno a qué consideran como “cultural” y qué representa la motivación “vacaciones/paseo” para esos turistas (siendo que no son excluyentes) los datos evidencian ese fuerte posicionamiento turístico asociado al patrimonio natural (Ministerio de Turismo de Misiones, 2014, p. 19). De esta manera, y atendiendo a esta precaución sobre las categorías utilizadas en la encuesta a la demanda, se puede de todos modos conjeturar una discordancia entre la oferta y los requerimientos de la demanda en torno a sus motivaciones, o, mejor dicho, se la puede considerar como oportunidad más que como una falencia, y en parte entonces como una fortaleza que aún no está potenciada. Ampliando entonces su forma de representación incluyendo al ambiente, podría posicionarse al destino contribuyendo a un equilibrio del desarrollo turístico, creando una oferta más integral, que por el momento se encuentra mayormente polarizado en las cataratas del Iguazú "Plan de competitividad turística del corredor Iguazú Misiones” (2007, pp. 22-23)

En síntesis, para contribuir al desarrollo integral y sostenible, la diversificación de la oferta turística debería construirse en sincronía con formas de comunicación multifacética de la cultura y del patrimonio. Así, el desarrollo de políticas patrimoniales y turísticas debería tender a 
concebir, planificar, gestionar y controlar de manera holística con el territorio, las identidades, las comunidades, el ambiente, otras actividades productivas, los marcos institucionales, los diversos actores, para no solo "preservar" un patrimonio para las generaciones futuras, sino como marco general de comprensión de la complejidad que implica un destino turístico.

\section{CONCLUSIONES}

En primera instancia, se concluyó que las Misiones Jesuíticas Guaraníes constituyen un antecedente de gran relevancia para la historia de la Argentina y del Mercosur. Las mismas se desarrollaron desde el año 1609 hasta 1767, momento de la expulsión de los jesuitas, y constituyen una experiencia histórica, religiosa, sociocultural, económica y territorial excepcional. Entender su complejidad implica trascender una comunicación patrimonial asociada a su relevancia arquitectónica para imbuirse en diversas dimensiones de análisis. La propuesta incorpora no circunscribir la experiencia patrimonial a sus aspectos religiosos o estilísticos, sino también a sus dimensiones político-económicas, sociales y culturales en simbiosis con su contexto natural. Eso que puede resultar evidente, no solo reviste una importancia analítica, sino que a la vez, y tal como se desarrolló, incide en los modos de desarrollo turístico. En efecto, unos de los aportes estuvo relacionado con incluir un análisis multifacético de la cultura que problematice cómo ciertos paradigmas de interpretación del patrimonio conllevan al establecimiento de distintos modelos de desarrollo turístico y afectan también así a las realidades de los destinos y sus comunidades.

En lo que concierne al análisis turístico, en base a la triangulación metodológica, se señaló un consenso bibliográfico que destaca la existencia de un bien con un gran valor histórico y que presenta grandes atributos de atractividad, pero que todavía tiene mucho para aportar en términos de desarrollo local y de desenvolvimiento turístico. En este sentido, pese a su máximo reconocimiento internacional a partir de su inscripción a la Lista de Patrimonio Mundial (UNESCO), en la práctica convive con múltiples contradicciones y dilemas que requieren ser abordados a los efectos de considerar un desarrollo sostenible. En este sentido, se concluye que el uso turístico del patrimonio jesuítico guaraní presenta una gran potencialidad y además cobra una relevancia destacada a los efectos de diversificar la estructura productiva regional y potenciar la 
integración regional pero que, al mismo tiempo, posee limitantes que impiden o al menos obstaculizan que se de esa sinergia positiva. Dichas limitantes, no podrían explicarse nunca a partir de su valor patrimonial ni a su atractividad turística solamente, sino de poner en juego las historias y los actores desde un enfoque integral y multidimensional. Es decir, si bien coexisten problemas de comercialización integral y sistémica en los sitios patrimonio mundial también se pusieron de manifiesto problemas socioeconómicos estructurales, que no están definidos exclusivamente por el turismo, sino por una matriz más abarcativa.

En lo que respecta a los pueblos originarios, se considera preciso remarcar el gran desafío que se tiene por delante. Si bien el turismo, en muchos casos, actúa como un medio/vía para el conocimiento e inclusión de etnias, esto no es un imperativo o una premisa que necesariamente se deba dar. Uno de los factores que tendrá una fuerte influencia en el "cómo" se dé la práctica turística es justamente la política planteada en términos de planificación y gestión, en la creación de condiciones para el uso y disfrute turístico. Si bien esto ha disminuido durante los últimos años, todavía persiste una visión turística que divorcia los valores históricoculturales con los ecológicos o naturales, como si fueran dos dimensiones excluyentes o productos turísticos que necesariamente deban ser diferentes. Por su parte, en lo específico del patrimonio cultural, todavía persiste una "oferta" o un uso turístico del patrimonio fuertemente asociado a los conjuntos arquitectónicos, es especial a lo tangible que se visualiza en las ruinas. Se requiere, en este sentido, seguir profundizando sobre la temática socioterritorial y ambiental de la región, incluyendo el estado de situación de las distintas comunidades, su interés en participar en iniciativas turísticas, el legado intangible jesuítico guaraní y, también, sobre la importancia del soporte físico y biológico del lugar; entendiendo como prioritario que las actividades turísticas consideren la capacidad de carga del destino y se definan los límites en términos de usos del suelo. Se trata, en definitiva, de un desafío del ambiente entendido en un sentido amplio, no solo limitado a la simple conservación de la naturaleza, sino de la puesta en valor de los valores socioambientales del territorio, en donde se liga la interacción sociedad-naturaleza a partir de los distintos contextos históricos y espaciales. 


\section{BIBLIOGRAFÍA}

Almiron, Analía.; Bertoncello, Rodolfo y Troncoso, Claudia (2006). Turismo, patrimonio y territorio. Una discusión de sus relaciones a partir de casos de Argentina. Estudios y Perspectivas en Turismo, Vol. 15, N² 2, CIET, Buenos Aires: 101-124.

Arancibia, Lorena y Pouey Vidal, Viviane (2014). Reflexiones sobre comunidades indígenas, patrimonio, identidad y pertenencia cultural: el caso de Chile y Brasil. Comenchingonia Virtual, Revista Electrónica de Arqueología, Vol. VIII, N 2: 191-217. Bartolomé, Miguel Alberto (2008). Oguerojerai (desplegarse). La etnogénesis del Pueblo Mbya-Guaraní. Ilha Revista de Antropología, Vol. 10; No 1: 105-140.

Bertoncello, Rodolfo (2008). Turismo y geografía: lugares y patrimonio natural-cultural de la Argentina. Ciccus.

Bittencourt, Pedro de Alcântara César y Veroneze Stigliano, Beatriz (2011). Misiones Jesuíticas - Guaraníes en Brasil. Un análisis de la interpretación patrimonial. Estudios y Perspectivas en Turismo, Vol. 20, CIET, Buenos Aires: 1389-1407.

Cammarata, Emilce Beatriz (2006). El turismo como práctica social y su papel en la apropiación y consolidación del territorio. En: América Latina: cidade, campo e turismo (pp. 351-366). CLACSO, Consejo Latinoamericano de Ciencias Sociales, San Pablo.

Cammarata, Emilce Beatriz (2010). Misiones: Turismo, paisaje en la frontera con Paraguay y Brasil. Universidad Nacional de Misiones; Argentina: 1-19.

Caruso, Sergio Adrián (2015). Análisis del proceso de creación de los Parques Nacionales en Argentina. Geograficando, 11(1).

Comparato, Gabriel (2016). El uso turístico del patrimonio JesuíticoGuaraní en Mercosur. Una oportunidad de integración regional. Tesis de Maestría. IIL - JURSOC - UNLP.

CRESPIAL (2013). Inventario del Universo Cultural Guaraní. UNESCO: 1-16.

Crivos, Marta, y Pochettino, María Lelia (2002). El Aporte Etnográfico en Estudios Interdisciplinarios acerca de la Relación Hombre- 
Entorno Natural (Comunidades Mbyá-Guaraní, Provincia De Misiones, Argentina). Etnobiología; No 2: 76-89.

Cubas, Silvia Raquel (2006). Desarrollo turístico local en el municipio de San Ignacio. Análisis desde una perspectiva social. Monografía de Grado de la Lic. en Turismo. Facultad de Humanidades y Ciencias Sociales. UNaM, Argentina.

Del Rio, Paula (2007). Patrimonio, Turismo Cultural y Calidad de Vida en el marco del Desarrollo Sustentable. Un caso de estudio: Reducción Jesuítica Santos Mártires del Japón. Sistema Jesuítico Guaraní. Provincia de Misiones, Argentina. Ciencias Sociales Online, Julio, Vol. IV, No. 2, Universidad de Viña del Mar - Chile: 54-66.

Descola, Philippe (2002). “La antropología y la cuestión de la naturaleza”. En: Repensando la naturaleza. Encuentros y desencuentros disciplinarios en torno a lo ambiental: 155-171. Palacio, Germán y Ulloa, Atrid coordinadores. Colombia: Editorial Panamericana Formas e Impresos.

PNUD (2013). Informe nacional sobre desarrollo humano 2013. Argentina en un mundo incierto: Asegurar el desarrollo humano en el siglo XXI. Buenos Aires: 1-146.

Dieckow, Liliana (2003). El circuito turístico de las misiones Jesuítico guaraníes. Situación actual y estrategias de desarrollo. Realidad, enigmas y soluciones en turismo; Año II, Vol. III, CONDET, Neuquén: 46-63.

Dieckow, Liliana y otros (2012). Los Impactos Económicos de las Políticas Turísticas: Desarrollo Local o Enclaves Turísticos El Caso Paradigmático De Santa Ana, Misiones, Argentina. Palermo Business Review, Special Issue, Buenos Aires: 149162.

García Canclini, Néstor (1999). Los usos sociales del Patrimonio Cultural. En: Patrimonio Etnológico. Nuevas perspectivas de estudio (pp.16-33). Encarnación Aguilar editor, Granada: Consejería de Cultura de la Junta de Andalucía.

INDEC (2010). Censo del Bicentenario Pueblos Originarios Región Nordeste Argentino. En: Censo Nacional de Población, Hogares y Viviendas. Datos recuperados de https://www.indec.gov.ar/index.asp el 24/08/16. 
Kramer, Ana maría (2006). Liderazgos guaraníes. Breve revisión histórica y nuevas notas sobre la cuestión. Avá; No 9, agosto: 11-27.

Kramer, Ana María (2013). Guaraníes en Misiones. Tierras y Bosques 2011. Nuevos escenarios para viejas cuestiones. Larivada Investigaciones en Ciencias Sociales, Vol. I, $\mathrm{N}^{\circ}$. I, Universidad Nacional de Misiones: 1-23.

Maeder, Ernesto (2005). Las Misiones jesuíticas de guaraníes. Dos siglos de historiografía y controversia. En: Educación y evangelización. La experiencia de un mundo mejor, $\mathrm{X}$ Jornadas internacionales sobre Misiones Jesuíticas. Carlos Page editor, Argentina: 13-20.

Manzanal, Mabel y otros (2011). Poder y conflicto en territorios del norte argentino. Estudios Socioterritoriales; Revista de Geografía, No9: enero-junio: 57-81.

Ministerio de Turismo de Misiones (2014). Estudio de Demanda. Datos recuperados de: http://www.misiones.tur.ar/cont.php?s=69 el $24 / 08 / 16$

Ministerio de Turismo de Misiones (2017). Estudio del Perfil del Turista Integrado 2017. Datos recuperados de: https://issuu.com/mktmintur-misiones/docs/provincia_completo_integrado el 20/06/18

Nogueira Dorneles, Carmen Regina (2007). O turismo, o reencontro e a redescoberta da região das Missões. Tesis de Doctorado. Faculdade de Filosofia, Letras e Ciências Humanas, Universidade de São Paulo.

Nogueira Dorneles, Carmen Regina y Burkhard, Daniela (2008). Políticas públicas de turismo para o desenvolvimento local/regional das Missões Jesuítico-Guaraní. Revista Eletrônica de Turismo Cultural, Vol. 02, $\mathrm{N}^{\circ}$ 02, Brasil: 1-32.

Páez, Sergio Luis Alberto (2013). Las reducciones jesuíticas-guaraníes como antecedente de organización espacial en la región misionera. Contribuciones Científicas GÆA, Vol. 25, Argentina: 165-173

Paredes, Silvia Liliana (2013, diciembre 05 - 07). Los mbya guaraníes y el turismo. Diagnóstico del estado de determinadas comunidades Mbya Guaraníes de la Provincia de Misiones, respecto a su relación con la actividad turística. En: XII 
Jornadas Nacionales de Investigación en Turismo y VI Simposio en Turismo, CONDET.

Restrepo, Eduardo (2007). Identidades: planteamientos teóricos y sugerencias metodológicas para su estudio. Jangwa Pana, 5(1), 24-35

Rivero, Beatriz y otros (2011). Planificación interpretativa en las misiones jesuíticas. Realidad, tendencias y desafíos en turismo, Año XI, Vol. 9, Octubre: 111-131.

Schweitzer, Alejandro Fabián (2009). Dinámicas espaciales y territorios de la integración en las fronteras del Iguazú. En: Le bassin du Río de la Plata au coeur du Mercosur pp. 313 - 330). Editions des PUM Presses Universitaires du Mirail / Collection Hespérides Amérique, Toulouse.

Secretaría de Turismo de la Nación (2007). Plan de competitividad turística del corredor Iguazú Misiones. Misiones: Argentina.

Silveira Alves, Carlos Augusto (2007). O caminho das missões e seus Peregrinos: Nova modalidade de produto turístico na Região das Missões. Tesis en Mestrado em Ciências Sociais, Programa de Pós-graduação em Ciências Sociais; Pontíficia Universidade Católica do Rio Grande Do Sul: Porto Alegre.

Vilmar Satur, Roberto y de Albuquerque Cavalcanti, Guilherme (2000). Competitividade econômica de uma região turística: estratégias e vantagens. Serie Texto para discussão, $\mathrm{N}^{\circ} 204$, Universidade Federal da Paraíba: 3-21.

Viñuales, Graciela María (2007). “Misiones jesuíticas de guaraníes (Argentina, Paraguay, Brasil)”. Apuntes: Revista de estudios sobre patrimonio cultural-Journal of Cultural Heritage Studies, Vol. 20, $\mathrm{N}^{\circ}$ 1: 108-125.

World Heritage Centre (1984). Jesuit Missions of the Guaranis: San Ignacio Mini, Santa Ana, Nuestra Señora de Loreto and Santa Maria Mayor (Argentina), Ruins of Sao Miguel das Missoes (Brazil). Recuperado de: http://whc.unesco.org/en/list/275 (26/07/17)

World Heritage Centre (2016). Operational Guidelines for the Implementation of the World Heritage Convention. Intergovernmental Committee for the Protection of the World Cultural and Natural Heritage, UNESCO, Paris, Francia. 
51 - REVISTA LÍDER No 35. DiCIEMBRE, 2019

Wright, Susan (1998). La politización de la cultura. Anthropology Today, 14(1), 1-19. 